\title{
RELIGIOSITY, SPIRITUALITY, AND SUBSTANCE ABUSE
}

by

THOMAS M. ALLEN

\begin{abstract}
A THESIS
Submitted in partial fulfillment of the requirements for the degree of Master of Science in the Department of Criminal Justice in the Graduate School of The University of Alabama
\end{abstract}

TUSCALOOSA, ALABAMA 
Copyright Thomas M. Allen 2009

ALL RIGHTS RESERVED 


\begin{abstract}
Religiosity and spirituality are concepts often considered means of reducing substance abuse and are employed in substance abuse recovery programs such as Alcoholics Anonymous. Substance abuse is a serious social problem in the United States, a country in which religiosity and spirituality have been subject to change and re-definition, especially since the social turmoil of the 1960s. This study utilized data from the 2004 General Social Survey to examine the effects of religiosity and spirituality on substance abuse and to understand that social bonding may mediate the effects of religiosity on substance abuse outcomes. Four substance abuse outcomes were examined: lifetime crack use, lifetime injection drug use, drinking problem in the past year, and illegal substance use in the past year. A three-stage multivariate logistic regression analysis was used to evaluate the effects of religiosity and spirituality on substance abuse outcomes as well the hypothesized mediating status of social bonding. The results show that, with few exceptions, religiosity was negatively associated with substance abuse. Further, social bonding variables did slightly mediate the negative relationship between religiosity and substance abuse. As expected, spirituality increased the odds of some measures of substance abuse after religiosity was controlled. Policy implications and further research are discussed.
\end{abstract}




\section{ACKNOWLEDGEMENTS}

I would like to thank everyone who has been instrumental in helping me complete this research project. First, I would like to thank my Savior Jesus Christ for providing for me, sustaining me, and surrounding me with a supportive family and faculty to assist me in every possible way. I am grateful for my wonderful wife Rebekah and for my parents for their unwavering support and encouragement. I would like to thank the University of Alabama Alumni Association for their support of me through a generous fellowship. I am also honored to thank the State of Alabama, ASIS, the National Purple Heart Association, the Department of Criminal Justice, the College of Arts and Sciences, and the Jordan Scholarship fund for their financial support of my education. I would also like to thank my committee members, Dr. Ariane Prohaska and Dr. Nick Stinnett for their willingness to serve on the thesis committee and for their valuable input into the project. Lastly, I would like to thank Dr. Celia Lo, the chair of the thesis committee, my friend, and my mentor. Her dedication to students in the Department of Criminal Justice has paid dividends in the lives of many, including my own. I greatly appreciate her commitment to student learning and the close community of the Criminal Justice Department. Her encouragement of teaching, research, and student involvement has created an environment of openness, professionalism, and high-quality education within the Department of Criminal Justice. The research that ultimately became this thesis is the culmination of the work, sacrifice, contribution, and support of countless individuals to whom I am forever indebted. 


\section{CONTENTS}

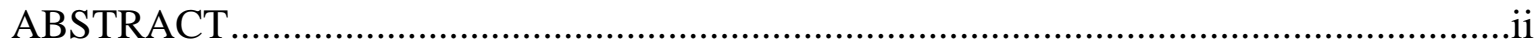

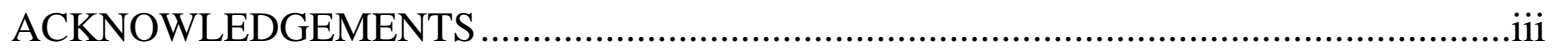

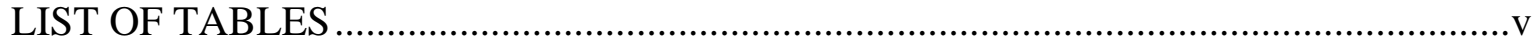

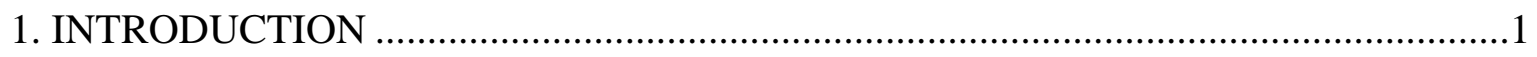

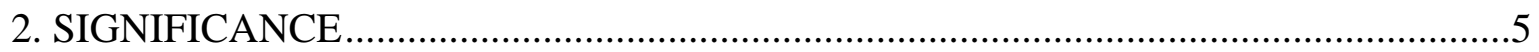

3. LITERATURE REVIEW AND HYPOTHESES ...........................................................

Religiosity and Spirituality ...................................................................................

Religiosity and Substance Abuse .................................................................................10

Religiosity, Social Bonds, and Substance Abuse............................................................11

Spirituality, Self, and Substance Abuse ..........................................................................13

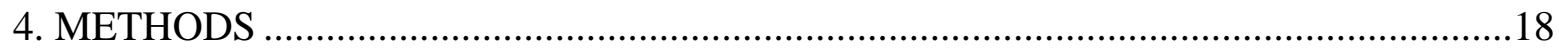

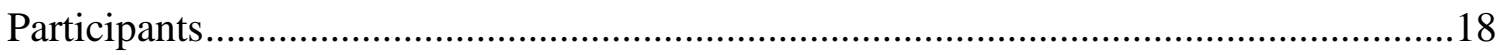

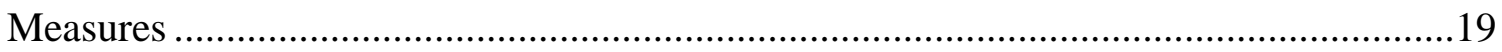

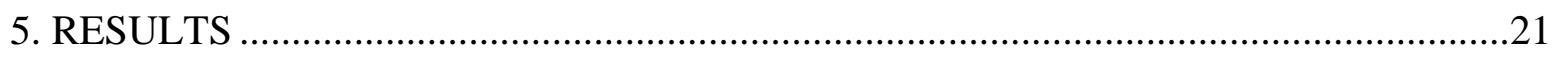

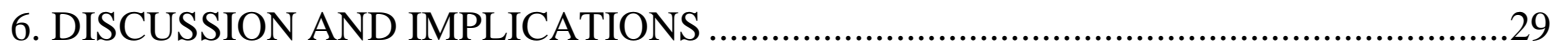

7. LIMITATIONS AND FUTURE DIRECTIONS.............................................................

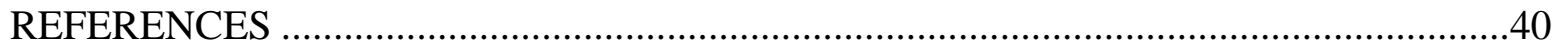

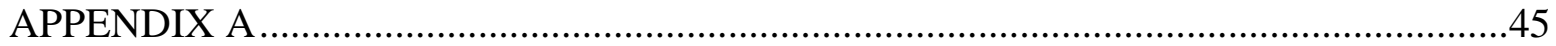




\section{LIST OF TABLES}

1. Correlation Coefficients, Means, and Standard Deviations of all Included Variables ......22

2. Logistic Regression of Lifetime Crack Use.....................................................................25

3. Logistic Regression of Lifetime Injection Drug Use.........................................................26

4. Logistic Regression of Reported Drinking Problem............................................................27

5. Logistic Regression of Reported Illegal Substance Use .......................................................28 


\section{CHAPTER 1}

\section{INTRODUCTION}

The abuse of substances by adults is a costly social problem in the United States. The National Institute on Drug Abuse (NIDA) claimed that drug abuse is linked to many adverse health effects such as infectious diseases like HIV, heart problems, respiratory problems, kidney and liver damage, abnormal brain functioning, cancer, and prenatal damage (National Institute on Drug Abuse , 2008). Additionally, drunk and drugged driving are responsible for the deaths of tens of thousands of Americans each year (NIDA). According to the Bureau of Justice Statistics, in 2004, drug offense prison sentences in the United States constituted the second longest group of sentences, after violent offenses (Bureau of Justice Statistics, 2008).

Further, the Drug Enforcement Administration claims that over 26,000 individuals in the United States died from drug-related causes in 2002 (Drug Enforcement Administration (DEA), 2006). The DEA cites other serious consequences of substance abuse such as the high cost of drug treatment, health care, law enforcement, and the cost of processing cases in the legal system. Additionally, death, illnesses, and drug-related crimes that affect individuals, families, and communities are also a result of drug use and abuse (Drug Enforcement Administration). It is therefore crucial to understand the factors associated with substance abuse with research that can provide insights into curbing it.

Scientific literature has explored the relationship between religiosity/spirituality and criminal and deviant behaviors increasingly since Hirschi and Stark’s (1969) work hypothesized yet did not find a negative relationship between measures of religiosity and juvenile delinquency. 
Religious beliefs and practices are common in the United States, and are often utilized in the treatment of and recovery from alcohol and drug abuse (Calhoun, 2007; Brown et al., 2007). It has been widely suggested that religious beliefs and behaviors may be protective factors against the abuse of substances. These beliefs and behaviors, both religious (social/doctrinal) and spiritual (individual connection to a higher power) are typically viewed as normative, conforming behaviors that should reduce the likelihood that an individual will participate in criminal or deviant behaviors, specifically substance abuse. At the individual level, both qualitative and quantitative research supported the claim that religiosity is negatively associated with substance abuse and is useful in the substance abuse recovery process (Brown, 2006; Bazargan, Sherkat, \& Bazargan, 2004). Miller (1998) put it simply: "There is strong evidence that spiritual/religious involvement is generally associated with decreased risk of alcohol/drug use, problems and dependence” (p. 981).

More recently, literature has focused on a new concept within the paradigm of socioreligious research; namely, spirituality (Ellingson, 2001; Weaver, Pargament, Flannely, \& Oppenheimer, 2006). Spirituality has most often been defined in terms of individual beliefs and practices related to God or a higher power in the universe, although these beliefs may also be entirely secular (Miller, 1998; Byfield \& Byfield, 1998; Mason, Singleton, \& Webber, 2007). In the United States and other parts of the world that consist of primarily Christian/Catholic cultures such as Western Europe and Australia, spirituality is being increasingly divorced from organized religions since the 1950s-1960s and the social turmoil associated with that period of time (Ellingson, 2001). More often, people are moving away from the church and their religious beliefs, and their spiritual practices are eclectic, secular, or not important (Byfield \& Byfield, 1998). It is also important to note that as individuals leave the church and as their participation 
in organized religions decreases, so does the social support provided by the church to individuals.

This research examined the relationships between religiosity, spirituality, and alcohol and illicit drug abuse. The purpose of this project was to determine if and how religiosity and spirituality affect drug and alcohol abuse. There has been extensive research on religiosity and crime and drug/alcohol abuse; however, the assumption that religiosity and spirituality are protective factors against deviant behavior has been criticized as spurious and requires empirical validation (Cochran, Wood, \& Arneklev, 1994; Evans, Cullen, Dunaway, \& Burton, 1995). Additionally, theoretical mechanisms that delineate the processes by which religiosity and spirituality influence substance abuse have not been common in the literature. Further, the conceptual overlap of religiosity and spirituality requires sophisticated statistical analyses to examine the various effects of religiosity and spirituality within a theoretical framework. Since spirituality ranges from being intertwined with and enhanced by religion to completely secular, it is important to account for this overlap.

It is important to examine the relationships between religiosity, spirituality, and adult drug and alcohol abuse because there is a widespread assumption that religious and spiritual factors are negatively related to drug and alcohol abuse; for example, the essence of the Alcoholics Anonymous program is individual reliance on God (Brown et al., 2007). Since the religious texts of the major world faiths proscribe illicit drug and alcohol abuse, it is expected that following these principles will lead to less frequent drug and alcohol abuse among religious 
adherents $^{1}$ (Miller, 1998). The purpose of this project was to examine the association between religiosity, spirituality, and drug and alcohol abuse in adults to determine the extent to which religiosity and spirituality serve to protect adults from abusing drugs and alcohol and to propose how this relationship can be reflected in both policy and community prevention/treatment programs.

\footnotetext{
${ }^{1}$ The Bible, in both the Old and New Testament, condemns drunkenness but does not demand total abstinence. See Ecclesiastes 10:17, Romans 13:13, and 1 Timothy 3:3 for examples in the Judeo-Christian tradition (New International Version used throughout). Islam is more proscriptive against alcohol use. Qur'an 2:219, for example, discusses the negative effects of intoxicants and proscribes their use. Illicit drug use is not only prohibited in Christianity through the prohibitions on drunkenness, but also indirectly because of the idea of respecting governmental authority (see 1 Peter 2:13).
} 


\section{CHAPTER 2}

\section{SIGNIFICANCE}

This research was significant and unique in several respects. First, following recent trends in scientific literature, this project conceptualized and measured religiosity and spirituality as different constructs that measure different beliefs and behaviors (Miller, 1998; Fernander, Wilson, Staton, \& Leukefeld, 2004; Neff, 2006). Secondly, this project employed multiple measures of both religiosity and spirituality due to the multidimensionality of those constructs (Miller, 1998; Freheit, Sonstegard, \& Schmitt, 2006; Neff, 2006; Berkel, Armstrong, \& Cokley, 2004). The limited and inconsistent range of measures of religiosity and spirituality has reduced reliability and has led to confusing, often contradictory results (Corwyn, Benda, \& Ballard, 1997). Therefore, multiple measures of both religiosity and spirituality, consistent with the theoretical model proposed and scientific literature, were used.

Thirdly, while much research has examined the roles of spirituality and religiosity in the juvenile context, this research focused on adults, in whom religiosity and spirituality are not under the direct influence of parents and the consequences of substance abuse are much more severe (Evans et al., 1995; Stack \& Kposowa, 2006). The predominance of religiosity studies among juveniles that measured religiosity by frequency of church attendance makes it risky to extrapolate from juvenile to adult behavior because of the issue of forced juvenile church attendance (Cochran, Beeghley \& Bock, 1988). This research extended the scientific literature on religion and substance abuse by studying illicit substances rather than alcohol alone in order to 
capture a fuller picture of factors related to substance abuse, especially since alcohol abuse is not illegal.

Further, the assumption that religiosity and spirituality are negatively related to substance abuse leads to an even greater need to quantitatively examine the operation of religiosity and spirituality in the context of drug and alcohol abuse, which is of primary importance in this research. It is easy to assume that being a "religious” or "spiritual” person makes someone less likely to abuse drugs and alcohol, and perhaps for this reason much of the literature on religion and behavior has failed to adequately examine the effects of religion from a theoretical perspective (Sumter, 2006; O’Connor, 2005). The theoretical neglect in the process of conducting research on religion and behavior has had several important consequences. As mentioned before, these include unreliable sampling methods, limited use of statistics-especially not including control and intervening variables, and an inconsistent and limited range of religiosity and spirituality measures (O’Connor, 2005; Evans et al., 1995; see Cochran et al., 1988 for a detailed summary of methodological concerns).

Religion has generally been assumed to have an effect on individual behavior, but much of the research has failed to define variables in a theoretical context and thus much of the literature in this area was inconsistent and has merited suggestions that the relationship between religion and anti-social and deviant variables is spurious (Cochran et al., 1994). Clearly, a theoretical model must be proposed when studying religion and behavior outcomes. This will lead to more valid, consistent, and replicable measures of religiosity and spirituality that provide a better understanding of the role of religious and spiritual constructs in influencing individual behaviors. This project was intended, theoretically and quantitatively, to delineate the social 
mechanisms leading from religiosity and spirituality to substance abusing behaviors, explaining the relationships between religiosity/spirituality and substance abuse among adults. 


\section{CHAPTER 3}

\section{LITERATURE REVIEW AND HYPOTHESES}

\section{Religiosity and Spirituality}

Religiosity is a complex, multidimensional construct and for the purpose of this project refers to the degree to which a person is religious from a primarily social and doctrinal perspective and is thus more easily quantifiable than abstract terms such as religion (Miller, 1998). Simply put, religiosity involves religious affiliation, participation, and association. Spirituality, on the other hand, is viewed from the perspective of the individual and his or her relationship to, connection with, and feelings about God or some higher power, and how this connection is related to an individual's search for self and meaning (Miller, 1998; Lesser, 2000). Again, however, it is not necessary for these beliefs to be shaped in any way by religious doctrine, and may be entirely secular for some individuals (Mason et al., 2007). Mann, McKeown, Bacon, Vesselinov, and Bush (2007) posited that:

Spirituality pertains to one's sense of connection to a transcendent power or purpose, with or without conformity to a set of prescribed beliefs or practices... Religiosity pertains to one's involvement in a system of worship and doctrine that is shared within a group. (p. 868)

The majority of recent literature reviewed for this project established a clear distinction between these two constructs (Miller, 1998; Fernander et al., 2004; Neff, 2006; Calhoun, 2007; Ellingson, 2001). This has not always been the case, however. Weaver et al. (2006) showed that in health research, there has been a significant increase in the number of scholarly articles focusing on spirituality, which is significant for this project in terms of how substance abuse is related to health. This is likely due at least in part to trends in American culture since the social 
turmoil of the 1960's that have placed less importance on organized religion and more on New Age and non-traditional spiritualities that focus more on self-actualization than religious doctrine and social organization (Ellingson, 2001). In the United States especially, the concepts of religion and spirituality are becoming increasingly divorced from one another (Rose, 2001). Eclectic or blended spiritualities are more common as individuals more or less pick and choose from the doctrines, practices, and beliefs that suit their interests (Byfield \& Byfield, 1998).

Religiosity is defined as a social phenomenon with an organized structure; however one purpose of most religions is to cultivate spirituality in its members, which causes an overlap between the concepts of spirituality and religiosity (Miller, 1998). For example, individual prayer is typically defined as a measure of spirituality; however individual prayer occurs within the context of religious services and in the private practices of individuals as part of their religious beliefs. In sum, it is impossible to create two distinct groups of people defined as either religious or spiritual; most people are characterized by elements of both, to varying degrees (Delaney, Miller, \& Bisono, 2007). Given the function of spirituality within religions and the trends in religiosity, it is reasonable to expect that people may be religious and spiritual or that they may be spiritual but not religious or that they may be neither. It is not expected that people will be religious but not spiritual, since spirituality is incorporated into religions and is manifested in practices such as prayer and worship. To understand how these constructs operate in a meaningful way, it is necessary to define them separately and to employ multiple measures because of their complex natures. Some of the more common measures of religiosity are denominational identification, frequency of participation in religious services, the meaningfulness of religion to an individual, and closeness to others in a religious group (Neff, 2006; Pullen, Modrcin-Talbott, West, \& Muenchen, 1999; Berkel et al., 2004). Measures of 
spirituality typically include one's belief in God or a higher power, individual prayer or meditation, the feeling of the presence or guidance of God in the midst of daily activities, and experiencing a connection to life (Miller, 1998; Fernander et al., 2004; Neff, 2006; Mann, McKeown, Bacon, Vesselinov, \& Bush, 2007).

Religiosity and Substance Abuse

Pioneering the research into the religiosity/delinquency relationship were Hirschi and Stark (1969), who predicted that through social control, church attendance would decrease juvenile delinquency. Interestingly, they failed to find a link between religiosity and delinquency. However, it is possible that the measures of religiosity used (juvenile church attendance and belief in the afterlife) did not validly or adequately measure religiosity, especially since juvenile religiosity can be confounded by other influences (Evans et al., 1995). The latter measure may have also been better termed a spiritual measure. Hirschi and Stark's finding that religiosity was not associated with less frequent delinquency provided the impetus for research into the effects of religion on criminal and deviant behaviors (Evans et al., 1995), which as previously discussed has been to some extent lacking in theoretical construction, even in recent literature.

Other more recent studies have examined religiosity and substance abuse. Miller (1998) found a significant relationship between individuals with alcohol and drug problems and a current lack of religious affiliation or participation. Pullen et al. (1999) found a similar relationship between church attendance and drug and alcohol use in juveniles. Likewise, in a study of inner-city emergency room patients, Bazargan et al. (2004) found that among several religious measures, religious participation was related to not having used alcohol within six 
hours of admission and also with abstinence from alcohol use, while no association was found with other religious/spiritual measures.

Michalak, Trocki, and Bond (2007) explored the relationship between religion and drinking behaviors via a secondary analysis of the 2000 National Alcohol Survey and found that drinking behaviors, especially total abstinence, were significantly correlated to measures of religiosity. Miller (1998) found that "religiously involved individuals are consistently less likely to use alcohol and other drugs, and when they do so are less likely to engage in heavy use and suffer its adverse consequences” (pp. 981-982). This statement was a good summation of many research findings that provided evidence that religiosity is associated with a lessened likelihood of engaging in substance abusing behaviors.

H1: Higher levels of religiosity will be associated with decreased odds of an individual ever having used crack cocaine, ever having injected illegal drugs, having used illegal drugs in the last year, and having a drinking problem in the last year.

Religiosity, Social Bonds, and Substance Abuse

Of primary importance in this research was to delineate the mechanism by which religiosity is related to substance abuse. There are a few pieces of literature that provided evidence for this mechanism, which may be explained by the presence of social bonding factors. First, Cochran et al. (1994) posited (for juveniles) that bonding variables such as school attachment and commitment and parental control are the means by which higher levels of religiosity are related to lower levels of delinquent behavior, and indeed found that for assault, theft, vandalism, illegal drug use, and truancy, the significant negative effects of religiosity were made insignificant when the bonding_variables were added. The significant effects of religiosity remained only for tobacco and alcohol use. Similarly, others have argued that the imposition of 
social bond variables such as nonreligious morality sources and legal deterrence, in addition to the effects of family and friends, helps to explain the relationship between religiosity and deviant, delinquent, and criminal behaviors (Johnson, Jang, Larson, \& De Li, 2001; Evans et al., 1995).

Stack and Kposowa (2006) proposed several theoretical explanations for the various frameworks in which religiosity is expected to deter deviant behavior. They claimed that religious bonds, formed through belief systems, would deter adult criminal behavior. The authors, studying the effects of religiosity on tax fraud acceptability, included in their model the bonds of marriage, work, and confidence in the government. All three bonding variables helped to predict outcomes of tax fraud acceptability. Importantly, religiosity may actually serve to enhance these bonds and this study highlighted the importance of including bonding variables in research on religiosity and deviant behavior.

Corwyn et al. (1997) challenged the bonding model with results that indicated that personal religiosity was a much better predictor of drug using outcomes than church attendance. Yet it is the social element of religiosity (like church attendance), rather than the individual element (termed spirituality in our research), that was suggested in the present research to bear significance in reducing drug use. They also found that religiosity was only relevant in contexts where religion was culturally common (Stack \& Kposowa, 2006) and where societal values were vague. There have clearly been mixed results not only in the effects of religiosity on deviant and especially substance abusing behaviors, but also in how religiosity may be related or unrelated to measures of bonding.

The social bonding mechanism has also been implicated especially in the study of African- American religiosity. Literature has specifically revealed a relationship between 
religiosity and civic involvement, positive relationships with others, social support, and facilitated access to health resources (Smetana and Metzger, 2005; Mattis, Murray et al., 2001; Wallace \& Bergeman, 2002). Further, studies of both African-Americans and Catholics, who tend to have a more social/communal orientation to practicing religion, have lent support to the argument that religiosity may operate through a social bonding process in influencing substance abusing behaviors (Neff, 2006; Cavendish, Welch, \& Leege, 1999).

There is no consensus on the best way to conceptualize the theoretical framework in which religiosity is related to substance abusing behaviors. There is theoretical and quantitative support for arguing that religiosity may operate through and even enhance broader social bonds that result in the individual decision to avoid abusing drugs and alcohol, and these bonds may be religious or secular.

H2: Social bonding variables will mediate the impact of religiosity on substance abusing behaviors.

Spirituality, Self, and Substance Abuse

As discussed previously, spirituality refers to an individual's connection to God or however they define a higher power in the universe, and also the individual beliefs and practices that accompany this connection. These may or may not be affiliated with any particular religious doctrine and may be entirely nonreligious. Indeed, American religion and spirituality are continuing to become conceptually different, as many people view religion as dry and too organized whereas spirituality has a more positive connotation and is, for many, cultivated apart from religious institutions, beliefs, and practices (Ellingson, 2001). This trend is significant not only in the study of religion and spirituality, but especially in criminology and sociology since religiosity and spirituality have social correlates in areas such as crime, substance abuse, the 
health of the family, physical and mental well-being, self-esteem, and coping (Cochran et al., 1994; Brown, 2006; Bazargan et al., 2004; Weaver et al., 2006; Wallace \& Bergeman, 2002; Park, Meyers, \& Czar, 1998; Cotton et al., 2006). Removing the social aspects of religiosity may result in unexpected outcomes in terms of the effects of spirituality.

Ellingson (2001) argued that the distance between religiosity and spirituality is especially apparent in the Baby Boomer generation, where a "spirituality of seeking,” rather than a spirituality of dwelling, is predominant. A spirituality of dwelling refers to a person finding God or the sacred within the context of doctrine and the religious institution. Conversely, a spirituality of seeking refers to an individual searching for the divine, meaning in life, and themselves through constantly seeking out information that can help them with immediate needs and problems. Although these individuals may or may not do this in the context of a group, they feel marginalized from groups (Ellingson). Spirituality, according to the author, is now related to self-growth, self-reliance, and the individual interpretation of right and wrong. He argued that a focus on "self-growth, self-healing, and self-actualization" and irreligious conceptualizations of God defeat the purpose of spirituality and liken it to a "therapeutic crutch" (p. 262). The purpose of this new spirituality then, is not a focus on God or the divine, but on the self.

Similarly, Rose (2001) described the differences between religiosity and spirituality and argues that spirituality does not necessarily promote conformity. He was consistent with Ellingson (2001) that within spirituality, it is much more up to the discretion of the individual to define existence, the divine, and morality. He also argued that belief systems such as Nazism even represent types of spirituality. Spirituality then is a much more loosely defined concept that tends to focus on the role of the self in seeking out truth in the universe, and these beliefs and 
practices have less and may even have nothing to do with traditional religious views on substance abuse and likely do not involve the same mechanism leading to deviance.

Nasel and Haynes (2005) also explored trends in spirituality. They found that the "new" spiritualities focus less on moral doctrine and encourage personal freedom and the self-definition of truth and morality. They argued that the ability of Christianity to represent and sustain one's spirituality has been declining and there is an upsurge of other spiritualities in the wake of this. These new spiritualities focus on the individual search for meaning and self, and the means by which they accomplish this are up to themselves. Their results showed a clear distinction between traditional Christians and proponents of New Age/unaffiliated spirituality. They concluded that traditional Christianity is more socially and doctrinally inclined whereas the new spiritualities focus on the experience and power of the individual. Consistent with their research was the discovery made by Park et al. (1998) that a significant empirical relationship exists between spirituality and self-actualization.

As discussed above, in their study of inner-city emergency room patients, Bazargan et al. (2004) did not find a significant relationship between higher levels of spirituality and lower odds of having used alcohol prior to admission, while certain measures of religiosity were associated with lower odds of alcohol use. This demonstrated the differential effects of religiosity and spirituality and that spirituality may not always be protective in terms of alcohol use. Interestingly, Hagekull (2007) found that positive parental attachment was related to higher levels of traditional religiosity in adulthood, whereas negative parental attachment was related to higher levels of New Age spirituality in adults, which is further evidence that spirituality, when is not enhanced by or related to religiosity, is related to the relatively lower levels of social bond factors and negative attachments. It was therefore expected that when elements of religiosity 
were taken into account, the remaining part of spirituality might not be negatively associated with substance abuse.

Lastly, some research has discovered that certain aspects of spirituality might increase the likelihood of substance abuse and even child abuse. There is research that supported the claim that more wrathful and fearful views of God or unstable and disappointing relationships with God may be related to higher likelihoods of substance and child abuse (Miller, 1998; Stewart \& Mezzich, 2006). It is likely that as individuals establish more and more distance from socially organized religions, their relationship with God will become more unstable and subject to change. Byfield and Byfield (1998) noted that in new spiritualities, individuals create God and morality, and are left to themselves to decide which path to choose, and that may be one of pleasure and individual fulfillment.

H3: When controlling for religiosity, higher levels of spirituality will be associated with increased odds of an individual ever having used crack cocaine, ever having injected illegal drugs, having used illegal drugs in the last year, and having a drinking problem in the last year.

This project was intended to further the scientific literature with a focus on religiosity, spirituality, and substance abuse by independently measuring religiosity and spirituality, including demographic variables that have been found to be related to substance abuse, and including measures of social bonds to better understand the social mechanism that is implicated in the relationship between religiosity and substance abuse. To examine the relationships between religiosity, spirituality, social bonds, and substance abuse in a theoretically sound and scientifically appropriate and consistent manner, this project was comprised of indexes that assess individual religiosity and spirituality, (Miller, 1998; Neff, 2006). The demographic variables that were controlled in this study were age, race, and sex. 
Age is an important demographic factor as literature shows young adults are more likely to abuse substances (Lambert, Gale, \& Hartley, 2008). Race is important to consider in light of the race-specific challenges that African-Americans face in terms of substance abuse exposure and recovery (Brown, 2006). Sex was included because males have been associated with higher levels of substance abuse and other criminal/deviant behaviors than females (Lo, Anderson, Minugh, \& Lomuto, 2006). The bonding variables measured an individual's stake in their families and communities and served as preventative measures against deviant behaviors such as substance abuse. In the present study, marital status and education level were intended to measure social bonding (Stack \& Kposowa, 2006). 


\section{CHAPTER 4}

\section{METHODS}

\section{Participants}

The current study employed a subset of data from the 2004 General Social Survey (GSS), conducted for the National Data Program for the Social Sciences regularly from 1972-2006 by the National Opinion Research Center, University of Chicago, with funding provided by the National Science Foundation (Davis, Smith, \& Marsden, 2007). GSS data have been frequently

used in scientific research, including studies of various aspects of religiosity (Cullen \& Unnever, 2006; Hamilton \& Form, 2003; Idler et al., 2003; Unnever, Cullen, \& Bartkowski, 2006). The GSS consisted of a full national probability sample (Davis et al., 2007). Some of the noted benefits of the 2004 survey were a larger sample size than previous surveys, more economic and racial diversity within the sample, and a wider variety of religious and spiritual measures (Unnever et al, 2006; Applegate, Cullen, Fisher, \& Ven, 2000). In 2004, the final sample included 2,812 (1,280 men and 1,532 women) non-institutionalized English-speaking adults aged 18 years and older. Additionally, about half of these individuals completed topical modules assessing more specific topics such as their religious and spiritual beliefs and behaviors. Beginning in 2004, surveys were completed through a computer-assisted personal interview (CAPI) with a reported response rate of approximately $71 \%$.

In the present study, about $13.4 \%$ of respondents were black, $79.4 \%$ were white, and 7.2\% were other races. Approximately $45.5 \%$ of respondents were male. In terms of religious preference, approximately 52.7\% of respondents were Protestant, 23.3\% were Catholic, .005 
were Orthodox Christian, .025 were Christian, 0.2\% were Jewish, 14.3\% had no religion, and the remainder, who comprised less than 1\% of the sample, were either Buddhist, Hindu, Muslim, Native American, belonged to another Eastern religion, or were inter-denominational.

Measures

Variables specifically related to religiosity, spirituality, social bonding, and substance abuse were included. Age, race, and sex were selected as control variables (Details of all included variables are shown in the Appendix A).

Four outcome variables measuring substance abuse were included: 1) drinking problem in the past year, 2) illegal substance use in the past year, 3) lifetime crack use, and 4) lifetime injection drug use. These dichotomous variables were re-coded to become dummy variables with " 1 ” indicating the presence of abuse and " 0 ” indicating its absence.

Religiosity was measured using four indicators that assessed religious fundamentalism, attendance, strength of religion, and feeling God's love through others. Fundamentalism and attendance were included as measures of religiosity because they described an individual's connection to an organized religion. The religious strength variable measured how strong an individual was in their religion; similar to fundamentalism, this measure assessed the degree to which a person was involved and connected to their religion. Lastly, the variable that assessed feelings of God's love through others measured how often a person had such feelings. These variables measured the social and doctrinal aspects of religion and their scores were summed to form the religiosity index. Fundamentalism, religious strength, and feeling God's love through others were re-coded so that lower values corresponded to lower levels of religiosity, which was found to have a moderate level of internal consistency (Alpha=0.68). 
Spirituality was measured using ten variables that assessed frequency of prayer, feeling God's love directly, asking for God's help, feeling God's guidance, feeling thankful for blessings, desiring to be closer to God, gaining strength from religion/spirituality, gaining comfort from religion/spirituality, feeling connected to all of life, and feeling joy that lifts a person out of daily concerns. In contrast to the measures of religiosity, these variables measured individual beliefs and behaviors that were not doctrinal and did not necessarily involve others. Their scores were summed to form the spirituality index. All of the measures in the spirituality index were re-coded so that lower values corresponded to lower levels of spirituality. A high level of internal consistency was recorded for this index (Alpha=0.95).

The measures of social bonding in the present study were the respondent's marital status $(0=$ not married, $1=$ =married) and the respondent's highest degree earned (ranged from $0=$ less than high school to 4=graduate degree). Three demographic variables were employed as control variables: age, race, and sex. Age was a continuous measure of age in years. The variable for race was collapsed as a dummy variable from the original measure to assess whether an individual was African-American (1) or non African- American (0). Sex was measured as a dummy variable with " 1 ” indicating male and “0” indicating female.

Logistic regression analysis techniques were used to test the hypotheses. A three-stage logistic regression analysis was employed to 1) evaluate the effect of religiosity on substance abuse, 2) examine the effect of spirituality on substance abuse after religiosity is controlled, and 3) understand if social bond variables mediate the effects of religiosity on substance abuse. 


\section{CHAPTER 5}

\section{RESULTS}

The means, standard deviations, and correlations were computed for all of the variables in the model and are reported in Table 1. The four outcome variables indicated low levels of substance abuse: 4.9\% reported lifetime crack use, 2.5\% reported lifetime injection drug use, 1.8\% reported having a drinking problem in the past year, and 5.8\% reported using illegal drugs in the past year. 
Table 1

Correlation Coefficients, Means, and Standard Deviations of all Included Variables

\begin{tabular}{|c|c|c|c|c|c|c|c|c|c|c|c|c|c|}
\hline Variable & (1) & (2) & (3) & (4) & (5) & (6) & (7) & (8) & (9) & (10) & Mean & $\begin{array}{c}\text { Std. } \\
\text { Deviation }\end{array}$ & $\mathrm{N}$ \\
\hline $\begin{array}{l}\text { Injection drug } \\
\text { use (1) }\end{array}$ & 1 & & & & & & & & & & 0.025 & 0.157 & 2224 \\
\hline Crack use (2) & $0.284^{* *}$ & 1 & & & & & & & & & 0.049 & 0.215 & 2225 \\
\hline $\begin{array}{l}\text { Problem } \\
\text { drinking (3) }\end{array}$ & 0.030 & $0.209 * *$ & 1 & & & & & & & & 0.018 & 0.133 & 1333 \\
\hline $\begin{array}{l}\text { Ilegal drug } \\
\text { use (4) }\end{array}$ & $0.196 * *$ & $0.297 * *$ & $0.136 * *$ & 1 & & & & & & & 0.058 & 0.234 & 1330 \\
\hline Age (5) & -0.028 & $-0.085^{* *}$ & $-0.064 *$ & $-0.162 * *$ & 1 & & & & & & 45.965 & 16.804 & 2803 \\
\hline Male (6) & $0.070 * *$ & $0.060 * *$ & $0.066^{*}$ & $0.136^{* *}$ & -0.019 & 1 & & & & & 0.455 & 0.498 & 2812 \\
\hline Black (7) & -0.017 & 0.017 & -0.014 & -0.050 & $-0.089 * *$ & $-0.054 * *$ & 1 & & & & 0.134 & 0.341 & 2812 \\
\hline Married (8) & $-0.050 *$ & $-0.085^{* *}$ & $-0.081^{* *}$ & -0.141 & $0.097 * *$ & 0.035 & $-0.153^{* *}$ & 1 & & & 0.526 & 0.499 & 2812 \\
\hline Degree (9) & $-0.054 *$ & $-0.108^{* *}$ & $-0.061 *$ & $-0.056^{*}$ & -0.036 & $0.049 * *$ & $-0.109 * *$ & $0.148^{* *}$ & 1 & & 1.611 & 1.207 & 2811 \\
\hline $\begin{array}{l}\text { Religiosity } \\
(10)\end{array}$ & $-0.091 * *$ & -0.031 & $-0.075 * *$ & $-0.154 * *$ & $0.109 * *$ & $-0.135 * *$ & $0.206^{* *}$ & $0.148^{* *}$ & $-0.081^{* *}$ & 1 & -0.007 & 3.057 & 1267 \\
\hline $\begin{array}{l}\text { Spirituality } \\
\text { (11) }\end{array}$ & -0.018 & 0.015 & -0.047 & $-0.142 * *$ & $0.118^{* *}$ & $-0.239 * *$ & $0.193^{* *}$ & $0.105^{* *}$ & $-0.111^{* *}$ & $0.741^{* *}$ & 0.014 & 8.310 & 1251 \\
\hline
\end{tabular}


When bivariate correlations were explored, significant and positive relationships were found among all outcome variables except for injection drug use and problem drinking. The social bonding variables measured by marital status and respondent’s highest degree earned had overall significant and negative relationships with all four outcome variables with the exception of injection drug use, in which marital status was not significant. A higher level of religiosity was strongly associated with a higher level of spirituality.

The strong correlation found between religiosity and spirituality called for a more indepth understanding of the relationship between these two variables. Therefore, a crosstabulation analysis was performed by dividing religiosity and spirituality into three categories: low, medium, and high. Respondents with scores equal to or less than one standard deviation below the mean were classified as having low levels of religiosity or spirituality. Respondents within one standard deviation above or below the mean were classified as having medium levels. Lastly, respondents with scores equal to or greater than one standard deviation above the mean were classified as having high levels of religiosity or spirituality. The results of the crosstabulation analysis showed that $40.6 \%$ of respondents reported high levels of religiosity and 53.2\% reported high levels of spirituality.

The results of the crosstabulation analysis showed that high levels of religiosity were associated with high levels of spirituality and low levels of religiosity were associated with low levels of spirituality; $88.2 \%$ of individuals with high religiosity had high levels of spirituality and $78.2 \%$ of individuals with low levels of religiosity had low levels of spirituality, for example. Interestingly, individuals with medium levels of religiosity tended to have either high or low levels of spirituality. Only about $13 \%$ of individuals with medium levels of religiosity had 
medium levels of spirituality. Almost 50\% of individuals with medium levels of religiosity had high levels of spirituality, and close to $40 \%$ of these respondents had low levels of spirituality.

To test our hypotheses about religiosity, spirituality, and substance abuse, it was necessary to perform a three-stage logistic regression analysis. In Stage 1, the substance abuse outcome was regressed on religiosity and the control variables. Stage 2 of the analysis included spirituality. Lastly, social bonding variables were added into Stage 3 of the logistic regression. The three-stage logistic regression analysis was performed for each of the four outcome variables: crack use, injection drug use, drinking problem, and illegal substance use. For the crack use outcome, religiosity exerted a negative effect in the Stage 2 and Stage 3 models (see Table 2). The odds ratio associated with the coefficient of religiosity in the Stage 3 model indicated that for every unit increase of religiosity, an individual was $14 \%$ less likely to have used crack in his or her lifetime. The negative relationship was slightly reduced by the inclusion of the social bonding variables indicating that social bonding variables mediated the impact of religiosity on lifetime crack use. When controlling for religiosity, spirituality significantly increased the likelihood that an individual had ever used crack by about 7.4\% (as shown in the final model in Table 2). Females were significantly less likely than males to have used crack cocaine. Age and race were not found to be significant in the final model. 
Table 2

Logistic Regression of Lifetime Crack Use

\begin{tabular}{|c|c|c|c|c|c|c|c|c|c|}
\hline & $\begin{array}{c}\text { Stage } \\
1 \\
\end{array}$ & & & $\begin{array}{c}\text { Stage } \\
2 \\
\end{array}$ & & & $\begin{array}{c}\text { Stage } \\
3 \\
\end{array}$ & & \\
\hline Variable & $\mathrm{b}$ & & Odds Ratio & $\mathrm{b}$ & & Odds Ratio & $\mathrm{b}$ & & Odds Ratio \\
\hline \multicolumn{10}{|l|}{ Controls } \\
\hline Age & -0.020 & & 0.981 & -0.021 & $*$ & 0.979 & -0.014 & & 0.986 \\
\hline Male & 0.793 & $* *$ & 2.209 & 0.943 & $* *$ & 2.568 & 0.987 & $* *$ & 2.684 \\
\hline Black & -0.017 & & 0.983 & -0.135 & & 0.874 & -0.313 & & 0.731 \\
\hline Religiosity & -0.025 & & 0.975 & -0.172 & $* *$ & 0.842 & -0.150 & * & 0.860 \\
\hline Spiritualtity & & & & 0.078 & $* *$ & 1.081 & 0.071 & $* *$ & 1.074 \\
\hline \multicolumn{10}{|c|}{ Social Bonding } \\
\hline Degree & & & & & & & -0.453 & $* *$ & 0.636 \\
\hline Married & & & & & & & -0.646 & $*$ & 0.524 \\
\hline Constant & -2.618 & $* *$ & 0.073 & -2.674 & $* *$ & 0.069 & -2.082 & $* *$ & 0.125 \\
\hline $\begin{array}{l}\text { Model Chi- } \\
\text { square }\end{array}$ & 11.946 & $*$ & & 19.040 & $* *$ & & 33.468 & $* *$ & \\
\hline Nagelkerke $\mathrm{r}^{2}$ & 0.037 & & & 0.061 & & & 0.106 & & \\
\hline
\end{tabular}

$* \mathrm{p}<.05$

$* * \mathrm{p}<.01$

As shown in the Stage 3 model of the injection drug use outcome, religiosity reduced the odds of lifetime injection drug use by about 31\%. Every unit increase in spirituality met with an increase in the likelihood of injection drug use by about $12.3 \%$. Males and non-married respondents were significantly more likely than females and married respondents to have injected drugs sometime in their lifetime. The bonding variable for educational achievement, age, and race were not significant in the Stage 3 model. 
Table 3

Logistic Regression of Lifetime Injection Drug Use

\begin{tabular}{|c|c|c|c|c|c|c|c|c|c|}
\hline & Stage 1 & & & Stage 2 & & & Stage 3 & & \\
\hline Variable & $\mathrm{b}$ & & Odds Ratio & $\mathrm{b}$ & & Odds Ratio & $\mathrm{b}$ & & Odds Ratio \\
\hline \multicolumn{10}{|l|}{ Controls } \\
\hline Age & -0.013 & & 0.987 & -0.013 & & 0.987 & -0.005 & & 0.995 \\
\hline Male & 0.940 & & 2.560 & 1.306 & $* *$ & 3.691 & 1.319 & $* *$ & 3.738 \\
\hline Black & -17.153 & & 0.000 & $17.400^{-}$ & & 0.000 & $17.605^{-}$ & & 0.000 \\
\hline Religiosity & -0.160 & $*$ & 0.852 & -0.395 & $* *$ & 0.674 & -0.371 & $* *$ & 0.690 \\
\hline Spiritualtity & & & & 0.122 & $* *$ & 1.130 & 0.116 & $* *$ & 1.123 \\
\hline \multicolumn{10}{|l|}{$\begin{array}{l}\text { Social } \\
\text { Bonding }\end{array}$} \\
\hline Degree & & & & & & & -0.165 & & 0.847 \\
\hline Married & & & & & & & -1.105 & $*$ & 0.331 \\
\hline Constant & -3.876 & $* *$ & 0.021 & -4.185 & $* *$ & 0.015 & -3.854 & $* *$ & 0.021 \\
\hline $\begin{array}{l}\text { Model Chi- } \\
\text { square }\end{array}$ & 16.821 & $* *$ & & 27.485 & $* *$ & & 33.689 & $* *$ & \\
\hline Nagelkerke ${ }^{2}$ & 0.088 & & & 0.144 & & & 0.176 & & \\
\hline
\end{tabular}

For the drinking problem outcome, religiosity and spirituality were not significant in the final model. Religiosity only significantly reduced the odds of the outcome in Stage 1 of the regression, prior to controlling for spirituality and social bonding effects. Married respondents were significantly less likely than non-married respondents to have had a drinking problem in the past year. Marital status was the only significant predictor of having a drinking problem in the final model. 
Table 4

Logistic Regression of Reported Drinking Problem

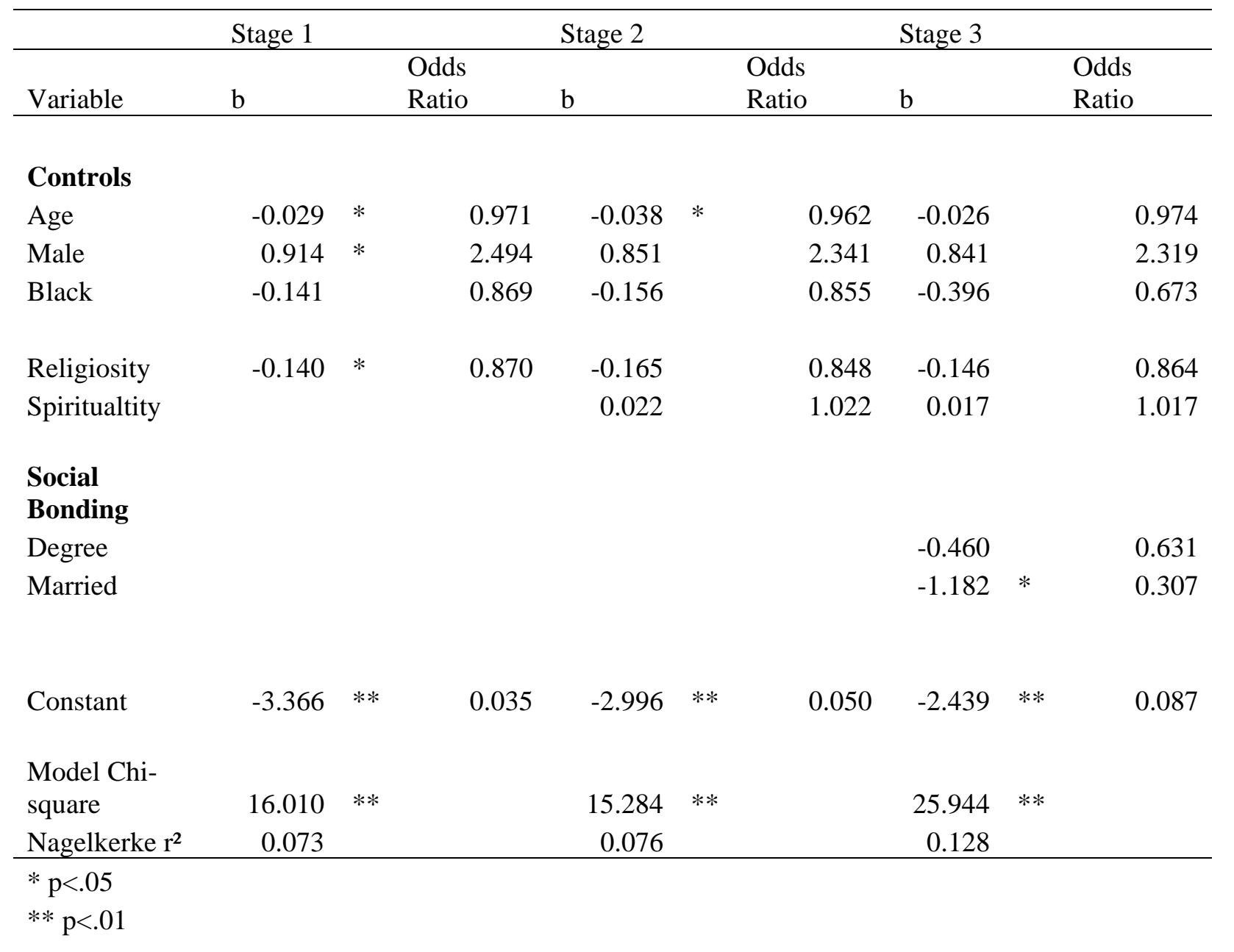

The logistic regression results concerning illegal substance use showed that religiosity reduced the odds of illegal substance use by about $15 \%$, while spirituality was not a significant factor. Respondents that were older, female, married, and with higher levels of education had significantly lower levels of illegal substance use than respondents who were younger, male, 
non-married, and that had lower levels of educational achievement in the final model. Race was not significantly related to the illegal substance use outcome.

Table 5

Logistic Regression of Reported Illegal Substance Use

\begin{tabular}{|c|c|c|c|c|c|c|c|c|c|}
\hline & Stage 1 & & & Stage 2 & & & Stage 3 & & \\
\hline Variable & $\mathrm{b}$ & & Odds Ratio & $\mathrm{b}$ & & Odds Ratio & $\mathrm{b}$ & & Odds Ratio \\
\hline \multicolumn{10}{|l|}{ Controls } \\
\hline Age & -0.052 & $* *$ & 0.949 & -0.055 & $* *$ & 0.947 & -0.044 & $* *$ & 0.957 \\
\hline Male & 1.111 & $* *$ & 3.038 & 1.044 & $* *$ & 2.840 & 1.031 & $* *$ & 2.804 \\
\hline Black & -0.639 & & 0.528 & -0.604 & & 0.547 & -0.797 & & 0.450 \\
\hline Religiosity & -0.170 & $* *$ & 0.844 & -0.168 & $* *$ & 0.846 & -0.158 & $* *$ & 0.853 \\
\hline Spiritualtity & & & & -0.003 & & 0.997 & -0.006 & & 0.994 \\
\hline \multicolumn{10}{|l|}{$\begin{array}{l}\text { Social } \\
\text { Bonding }\end{array}$} \\
\hline Degree & & & & & & & -0.275 & $*$ & 0.759 \\
\hline Married & & & & & & & -0.888 & $* *$ & 0.411 \\
\hline Constant & -1.477 & $* *$ & 0.228 & -1.357 & $* *$ & 0.257 & -1.028 & $*$ & 0.358 \\
\hline $\begin{array}{l}\text { Model Chi- } \\
\text { square }\end{array}$ & 83.413 & $* *$ & & 81.376 & $* *$ & & 97.552 & $* *$ & \\
\hline Nagelkerke $r^{2}$ & 0.179 & & & 0.182 & & & 0.217 & & \\
\hline
\end{tabular}

$* \mathrm{p}<.05$

$* * \mathrm{p}<.01$ 


\section{CHAPTER 6}

\section{DISCUSSION AND IMPLICATIONS}

The purpose of this study was to understand the disparate effects of religiosity and spirituality on substance abuse and to examine for the possible mediating role that social bonding might play in the relationship between religiosity and substance abuse. Four substance abuse outcomes were included in this study. Lifetime crack use and injection drug use measures assessed whether or not an individual had ever used crack or injected drugs. Measures of drinking problems and illegal substance use respectively measured if a respondent had a drinking problem or used illegal substances in the past year.

Religiosity is a social and doctrinal assessment of a person's religion, which includes measures such as frequency of attendance at worship services and the relative fundamentalism of a person's religion (Miller, 1998). Spirituality, on the other hand, refers to individual beliefs and behaviors, such as prayer frequency and feelings of connection to God (Miller). Since a function of religious groups is very often to enhance the spirituality of its members, there is considerable overlap between these two concepts (Fisher, Francis, \& Johnson, 2002). Therefore, this study was conducted by measuring religiosity and spirituality as both highly related yet somehow different concepts whose effects must be untangled and separated to examine individually. In addition, this study was conducted in a multivariate context, which has not often been seen in other studies of substance abuse explained by religiosity and spirituality.

Based on a review of literature, we hypothesized that religiosity would significantly reduce the odds of substance abuse (Miller 1998; Brown, 2006; Bazargan et al., 2004). Some 
literature indicated that spirituality and viewing God fearfully was associated with higher levels of substance abuse and even child abuse (Miller, 1998; Stewart \& Mezzich, 2006). Researchers proposed a social mechanism linking spirituality to higher levels of individualism and selfactualization, exerting a positive impact on substance abuse (Park et al., 1998; Ellingson, 2001; Rose, 2001). While no good measures of individualism and self-actualization could be found in the data, spirituality was hypothesized in the present study to increase the odds of substance abuse after religiosity was controlled.

The correlation coefficients revealed some interesting results about the variables (See Table 1). Most of the outcome variables were significantly and positively correlated. However, non-significant correlations were found between problem drinking and injection drug use. This may be due to the fact that injection drug use measured serious, illegal drug abusing behaviors while the problem drinking variable measured relatively less serious and legal activities. Religiosity and the social bonding variables were negatively associated with the substance abuse outcomes in bivariate correlations as expected. Interestingly, even at the bivariate level, the differences between religiosity and spirituality emerged. Spirituality only significantly reduced illegal substance use in the past year and was not found to be significant for any other substance abuse outcome.

The crosstabulation analysis allowed us to further explore the seemingly complicated relationship between religiosity and spirituality. As stated previously, individuals were divided into groups where they were identified as having either low, medium, or high levels of religiosity and spirituality. Those with high and low levels of religiosity tended to have respective levels of spirituality; however those with medium levels of religiosity tended to have either high or low levels of spirituality. 
Spiritualities that are blended with several different belief systems and possibly even (several) organized religious groups may be responsible for the groups of individuals that have medium levels of religiosity and high levels of spirituality, since they may be participating in some religious services from different faith backgrounds while simultaneously defining, creating, and practicing their own spirituality (Byfield \& Byfield, 1998).

Conversely, those individuals with medium levels of religiosity and low levels of spirituality may be indicative of groups of people that are participating in religious activities in a more ritualistic manner. This has implications for the value of religious groups and institutions, which, for many Americans, seem to be losing influence (Nasel \& Haynes, 2005). This loss of influence is particularly true of Christianity, as it is the major religion in the United States. The social and cultural patterns within Christianity that include blended spiritualities and an acculturated version of Christianity may account for individuals with medium levels of religiosity and either high or low levels of spirituality.

Geering (2001) pictured modern Christianity as less relevant and now a "fluid cultural stream...that has the capacity to meet the needs of the emerging global culture (p. 12). In the same way that the word "Jewish" can refer to a culture and a religion, the steady departure from organized religion in the United States has created a context in which the word "Christian" is becoming a cultural term as well as a statement of personal faith in Jesus Christ. For example, the celebration of Christmas is not restricted to celebrating the birth of Jesus, but for many people in the United States and globally is a celebration of family (Geering).

Individuals who pick and choose religion(s) and spiritualities for their own interests may be likely to have medium levels of religiosity and high levels of spirituality, as the 
crosstabulation analysis showed. "Cultural” Christians, on the other hand, may have medium levels of religiosity and low levels of spirituality.

We performed two t-tests comparing Christianity to religiosity and spirituality due to the close relationship between religiosity and spirituality and the prevalence of Christianity in the United States. We created a dummy variable for religious preference that distinguished between Christians and non-Christians in which the original response categories "Protestant," "Catholic," “Orthodox Christian," and "Christian” were re-coded as "1" and all other religious preference responses were coded "0". Significant mean differences were found between Christians and non-Christians in religiosity and spirituality. People who had Christianity as their religious preference were also associated with higher levels of religiosity and spirituality when compared with non-Christians. Clearly, religiosity, spirituality, and Christianity are all interconnected yet somehow different in the United States, especially in the last 50 years.

In this context, we examined the effects of religiosity and spirituality on substance abuse in a multivariate model in which social bonding variables played a role in mediating the effects of religiosity on substance abuse. We hypothesized that higher levels of religiosity would be associated with a lower likelihood of substance abuse. This hypothesis was supported for every substance abuse outcome except for the drinking problem outcome. This may have been due to the fact that the drinking problem outcome represented the only dependent variable that was a legal (and also less serious) behavior. While Cochran et al. (1994) predicted that religiosity would be more influential in reducing less serious behaviors that society as a whole tends to be ambivalent about (such as marijuana use), this study actually showed religiosity to be more effective at reducing the odds of more serious substance abuse such as crack use and injection drug use. Consistent with Cochran et al., however, were this study's findings that higher levels 
of religiosity also reduced the likelihood of the less serious outcome of illegal substance use in the past year.

The second hypothesis indicated that the observed negative relationship between religiosity and substance abuse would be mediated by the inclusion of social bonding variables. For all of the outcomes where religiosity was significant, (all but the drinking problem outcome) social bonding effects did slightly mediate the negative impact of religiosity on substance abuse. The inclusion of social bonding variables also slightly mediated the positive effects of spirituality, which may be attributed to the fact that religiosity and spirituality are highly related concepts. In addition, social bonding may actually lead the spiritual respondents from marginalizing themselves from social groups and networks, reducing the positive impact exerted by spirituality on substance abuse among adults.

While religiosity was found to have a negative impact on substance abuse, the present study hypothesized that spirituality would actually increase the odds of substance abuse after the effects of religiosity were taken into account (H3). This hypothesis was supported for the more serious substance abuse outcomes, crack use and injection drug use, but not for the less serious outcomes of having a drinking problem and using illegal substances. Alcohol is a less serious and legal substance and is generally more acceptable. Spirituality was also not a significant predictor of illegal substance use. For many Americans, this illegal substance is likely to be marijuana (Bureau of Justice Statistics, 2008) which is another less serious, however illegal substance.

It is interesting that spirituality was found to be significant for the more serious substance abuse outcomes but not for the less serious ones. Since alcohol is a relatively mild substance, the non-significance of spirituality in relation to the drinking problem outcome may be attributed to 
the cultural view of alcohol as a permissible substance, used often in social settings. In a similar way, an increasing social ambivalence towards marijuana use may contribute to spirituality’s non-significant relationship to less serious substance abuse outcomes. Conversely, spirituality did significantly increase the odds of the more serious substance abuse outcomes of lifetime crack use and injection drug use. Some studies have indicated that factors such as selfactualization and individualism are inherent in some types of spirituality, especially newer, blended spiritualities (Ellingson, 2001; Miller, 1998). These are two specific pathways that may connect spirituality to substance abuse that should be explored in future studies. Further, viewing God fearfully and as wrathful, as one of the measures of our spirituality index, might have also exerted positive effects on deviancy (Stewart \& Mezzich, 2006). Since individuals who are from different religious backgrounds and who participate in different forms of spirituality are likely to differ on how they conceptualize God, it is possible that disparate views of God may also play a critical role in linking spirituality to deviant and criminal behaviors.

This study has implications for policies and practices currently employed in the recovery from substance abuse problems. This includes 12-step programs such as Alcoholics Anonymous and Narcotics Anonymous in which religiosity and spirituality are employed. While these and other programs like them are not affiliated with a particular religious group, their success may be attributable to the social support structure that is created within a spiritual environment. Programs utilize different aspects of religiosity and spirituality, such as belief in God or a higher power, submission to God, connection to others, and prayer (Alcoholics Anonymous, 2009b). They also provide a clearly defined social support network in which group members meet together for mutual encouragement and accountability, and therefore can reasonably be expected to help individuals recover from substance abuse problems (Alcoholics Anonymous, 2009a). 
Further, these programs may also have success stemming from their ability to suppress individualism that may be related to spirituality, when the effects of religiosity are controlled. For example, one of the steps in the Alcoholics Anonymous program encourages participants to recognize their own powerlessness and to attempt to turn their lives and wills over to God (2009b). Programs that have a God-first or group-first mentality may be able to counter the positive effects that spirituality may have on substance abuse.

Individuals may also seek help in substance abuse recovery directly from religious groups. Therefore, this study also has implications for those groups being vehicles of support and networking for individuals dealing with substance abuse problems. While these groups are able to disseminate information, provide counseling and social support, and be a source of religious enhancement, they may be especially effective in helping individuals recover from substance abuse. Brown (2006) showed that religion and church attendance were crucial in the lives of African-American women who were attempting to quit abusing crack cocaine. Likewise, other religious groups may also be instrumental in creating an environment of social support in which individuals dealing with substance abuse problems can recover (Smetana \& Metzger, 2005; Mattis et al., 2001).

The present study has implications for the future study of religiosity and spirituality, especially in the context of substance abuse and deviancy. The multivariate models used in this study shed new light into the effects of religiosity and spirituality on substance abuse, and showed that religiosity and spirituality are very closely related yet conceptually different concepts that have disparate effects on substance abuse. Future studies should consider using a similar multivariate context to further unravel the complicated relationship between religiosity 
and spirituality and how those factors influence other types of deviance. Further, future studies should attempt to delineate the mechanisms that link spirituality to substance abuse. 


\section{CHAPTER 7}

\section{LIMITATIONS AND FUTURE DIRECTIONS}

Limitations inherent in secondary data analysis were present in this study. The measures of religiosity and the social bonding measures were limited. The religiosity index contained four measures, and could have been improved with other measures such as connection to others within a religious group. Other social bonding measures such as group involvement would have also contributed to a fuller picture of social bonding; however the measures used still provided enough information with which to build a suitable model and empirically see the disparate effects of religiosity and spirituality as well as the mediating effect that social bonding has on the relationship between religiosity and substance abuse.

We also lacked optimal measures for the substance abuse outcomes. The frequency of substance use was not measured and the illegal substance abuse variable did not specify which drug was used, although marijuana is the most frequently used illegal drug in the United States (Bureau of Justice Statistics, 2008). More measures of substance abuse that are more specific as to the drug and frequency of use will be useful in future studies concerning the effects of religiosity and spirituality on substance abuse and misuse. Without longitudinal data it was not possible to establish cause and effect relationships between religiosity, spirituality, and substance abuse because individuals with past drug problems could have turned to religion as a means of coping with and recovering from substance abuse problems (Brown, 2006). Future studies should attempt to collect and utilize longitudinal data to account for the temporal order of these variables. 
This project was unique in its utilization of a multivariate model that enabled us to separate the effects of religiosity and spirituality based on literature that has defined religiosity and spirituality independently and that has shown religiosity and spirituality to operate differently in several deviant and criminal outcomes, including substance abuse (Miller, 1998; Stewart \& Mezzich, 2006; Park et al., 1998; Ellingson, 2001). Further, this study was comprised of adults, a population in which the consequences of substance abuse are especially detrimental and also one in which we feel confident that the measures of religiosity and spirituality may be more accurate than juvenile populations in which the risk for the confounding effects of parental religiosity and spirituality could be present (Cochran, Beeghley \& Bock, 1988). Lastly, the present study employed a theoretical model drawn from evidence in the literature from which our hypotheses were constructed.

This research was significant in providing empirical evidence that spirituality may increase the likelihood for substance abuse when religiosity is controlled. This was perhaps the most important finding of the study, and one that is, at first glance, counter-intuitive. Unfortunately, in this study there were no appropriate measures, such as measures of individualism and self-actualization, in the data to empirically understand why this might be the case. However, the theoretical basis for the study and the literature indicated that when the effects of religiosity are controlled, spirituality may have effects that are opposite of what may be expected. Future studies should explore this further to assess what aspects of spirituality that are not related to religiosity may increase the likelihood for substance abuse and to describe the mechanism that links spirituality to substance abuse. Substance abuse treatment in the United States has not been very successful, and the findings of the present study may help. This knowledge will be significant in understanding how and why recovery programs utilize these 
concepts to improve success rates, how religious groups may be integral in the recovery process, and how to best apply the concepts of religiosity and spirituality to substance abuse avoidance and recovery. 


\section{REFERENCES}

Alcoholics Anonymous (2009a). A.A. at a glance. Retrieved February 11, 2009, from http://www.aa.org/pdf/products/f-1_AAataGlance1.pdf

Alcoholics Anonymous (2009b). A brief guide to Alcoholics Anonymous. Retrieved February 11, 2009, from http://www.aa.org/pdf/products/p-42_abriefguidetoaa.pdf

Applegate, B., Cullen, F., Fisher, B., \& Ven, T. (2000). Forgiveness and fundamentalism: Reconsidering the relationship between correctional attitudes and religion. Criminology, 38, 719-751.

Bazargan, S., Sherkat, D., \& Bazargan, M. (2004). Religion and alcohol use among AfricanAmerican and Hispanic inner-city emergency care patients. Journal for the Scientific Study of Religion, 43(3), 419-428.

Berkel, L., Armstrong, T., \& Cokley, K. (2004). Similarities and differences between religiosity and spirituality in African American college students: A preliminary investigation. Counseling and Values, 49, 2-14.

Brown, E. (2006). The integral place of religion in the lives of rural African American women who use cocaine. Journal of Religion and Health, 45(1), 19-39.

Brown, A., Pavlik, V., Shegog, R., Whitney, S., Friedman, L., Romero, C., Davis, G., Cech, I., Kosten, T., \& Volk, R. (2007). Association of spirituality and sobriety during a behavioral spirituality intervention for twelve step (TS) recovery. American Journal of Drug \& Alcohol Abuse, 33(4), 611-617.

Bureau of Justice Statistics (2008). Criminal sentencing statistics. Retrieved December 15, 2008, from http://www.ojp.usdoj.gov/bjs/sent.htm.

Byfield, T., \& Byfield, V. (1998). In today’s eclectic “spirituality,” God doesn’t create us, we create God. Alberta Report/Newsmagazine, 25(33), 33.

Calhoun, F. (2007). Developmental research on alcohol and spirituality: What we know and what we don’t know. Southern Medical Journal, 100(4), 427-429.

Cavendish, J., Welch, M., \& Leege, D. (1999). Social network theory and predictors of religiosity for black and white Catholics: Evidence of a "black sacred cosmos?” Journal for the Scientific Study of Religion, 37(3), 397-410. 
Cochran, J., Beeghley, L., \& Bock, E. (1988). Religiosity and alcohol behavior: An exploration of reference group theory. Sociological Forum, 3(2), 256-276.

Cochran, J., Wood, P., \& Arneklev, B. (1994). Is the religiosity-delinquency relationship spurious? A test of arousal and social control theories. Journal of Research in Crime \& Delinquency, 31(1), 92-123.

Corwyn, R., Benda, B., \& Ballard, K. (1997). Do the same theoretical factors explain alcohol and other drug use among adolescents? Alcoholism Treatment Quarterly, 15(4), 47-62.

Cotton, S., Puchalski, C., Sherman, S., Mrus, J., Peterman, A., Feinberg, J., Pargament, K., Justice, A., Leonard, A., \& Tsevat, J. (2006). Spirituality and religion in patients with HIV/AIDS. Journal of General Internal Medicine, 21, S5-13.

Cullen, F., \& Unnever, J. (2006). Christian fundamentalism and support for capital punishment. Journal of Research in Crime and Delinquency, 43(2), 169-197.

Davis, J., Smith, T., \& Marsden, P. (2007). General Social Surveys, 1972-2006 [CUMULATIVE FILE] [Computer file]. ICPSR04697-v2. Chicago, IL: National Opinion Research Center [producer], 2007. Storrs, CT: Roper Center for Public Opinion Research, University of Connecticut/Ann Arbor, MI: Inter-university Consortium for Political and Social Research [distributors], 2007-09-10.

Delaney, H., Miller, W., \& Bisono, A. (2007). Religiosity and spirituality among psychologists: A survey of clinician members of the American Psychological Association. Professional Psychology: Research and Practice, 38(5), 538-546.

Drug Enforcement Administration (2006). Costs to society. Retrieved March 5, 2009, from http://www.justthinktwice.com/costs/

Ellingson, S. (2001). The new spirituality from a social science perspective. Dialog: A Journal of Theology, 40(4), 257-263.

Evans, T., Cullen, F., Dunaway, R., \& Burton, V. (1995). Religion and crime reexamined: The impact of religion, secular controls, and social ecology on adult criminality. Criminology, 33(2), 195-224.

Fernander, A., Wilson, J., Staton, M. and Leukefeld, C. (2004). An exploratory examination of the spiritual well-being scale among incarcerated black and white male drug users. International Journal of Offender Therapy \& Comparative Criminology, 48(4), 403-413.

Fisher, J., Francis, L., \& Johnson, P. (2002). The personal and social correlates of spiritual wellbeing among primary school teachers. Pastoral Psychology, 51(1), 3-11. 
Freheit, S., Sonstegard, K., \& Schmitt, A. (2006). Religiosity and spirituality: A psychometric evaluation of the Santa Clara strength of religious faith questionnaire. Pastoral Psychology, 55, 27-33.

Geering, L. (2001). An ecological faith for the global era. Ecothelogy, 6(1/2), 12-22. Hagekull, B. (2007). Examining relations among attachment, religiosity, and new age spirituality using the adult attachment interview. Developmental Psychology,43(3), 590-601.

Hagekull, B. (2007). Examining relations among attachment, religiosity, and new age spirituality using the adult attachment interview. Developmental Psychology, 43(3), 590601.

Hamilton, R., \& Form, W. (2003). Categorical usages and complex realities: Race, ethnicity, and religion in the United States. Social Forces, 81(3), 693.

Hirschi, T. \& Stark, R. (1969). Hellfire and delinquency. Social Problems, 17, 202-214.

Idler, E., Musick, M., Ellison, C., George, L., Krause, N., Ory, M., Pargament, K., Powell, L., \& Williams, D. (2003). Measuring multiple dimensions of religion and spirituality for health research: Conceptual background and findings from the 1998 General Social Survey. Research on Aging, 25(4), 327-365.

Johnson, B., Jang, S., Larson, D., \& De Li, S. (2001). Does adolescent religious commitment matter? A reexamination of the effects of religiosity in delinquency. The Journal of Research in Crime and Delinquency, 38(1), 22-46.

Lambert, D., Gale, J., \& Hartley, D. (2008). Substance abuse by youth and young adults in rural America. Journal of Rural Health, 24(3), 221-228.

Lesser, E. (2000). Twenty-first century spirituality. Tikkun, 15(1), 22-23.

Lo, C., Anderson, A., Minugh, P., \& Lomuto, N. (2006). Protecting Alabama students from alcohol and drugs: A multi-level modeling approach. Journal of Drug Issues 36(3), 687718.

Mann, J., McKeown, R., Bacon, J., Vesselinov, R., \& Bush, F. (2007). Religiosity, spirituality, and tobacco use by pregnant women. Southern Medical Journal, 100(9), 867-872.

Mason, M., Singleton, A., \& Webber, R. (2007). The spirituality of young Australians. International Journal of Children’s Spirituality, 12(2), 149-163.

Mattis, J., Murray, Y., Hatcher, C., Hearn, K., Lawhon, G., Murphy, E., \& Washington, T. (2001). Religiosity, spirituality, and the subjective quality of African American men's friendships: An exploratory study. Journal of Adult Development, 8(4), 221-230. 
Michalak, L, Trocki, K., \& Bond, J. (2007). Religion and alcohol in the U.S. National Alcohol Survey. Drug \& Alcohol Dependence, 87, 268-280.

Miller, W. (1998). Researching the spiritual dimensions of alcohol and other drug problems. Addiction, 93(7), 979-990.

National Institute on Drug Abuse (2008). Medical consequences of drug abuse. Retrieved October 20, 2007, from http://www.nida.nih.gov/consequences/

Nasel, D., \& Haynes, D. (2005). Spiritual and religious dimensions scale: Development and psychometric analysis. Australian Journal of Psychology, 57(1), 61-71.

Neff, J. (2006). Exploring the dimensionality of "religiosity" and "spirituality" in the Fetzer multidimensional measure. Journal for the Scientific Study of Religion, 45(3), 449-459.

O'Connor, T. (2005). What works, religion as a correctional intervention: Part II. Journal of Community Corrections, 14, 4-26.

Park, J., Meyers, L., \& Czar. G. (1998). Religiosity and spirituality: An exploratory analysis using the CPI 3-vector model. Journal of Social Behavior and Personality, 13(3), 541552.

Pullen, L., Modrcin-Talbott, M., West, W., \& Muenchen, R. (1999). Spiritual high vs high on spirits: Is religiosity related to adolescent alcohol and drug abuse? Journal of Psychiatric and Mental Health Nursing, 6, 3-8.

Rose, S. (2001). Is the term 'spirituality' a word that everyone uses, but nobody understands what anyone means by it? Journal of Contemporary Religion, 16(2), 193-207.

Smetana. J., \& Metzger, A. (2005). Family and religious antecedents of civicinvolvement in middle class African American late adolescents. Journal of Research on Adolescence, 15(3), 325-352.

Stack, S., \& Kposowa, A. (2006). The effect of religiosity on tax fraud acceptability: A crossnational analysis. Journal for the Scientific Study of Religion, 45(3), 325351.

Stewart, C., \& Mezzich, A. (2006). The effects of spirituality and religiosity on child neglect in substance abuse disorder families. Journal of Family Social Work, 10(2), 35-57.

Sumter, M. (2006). Faith-based prison programs. Criminology and Public Policy, 5(3), 523528.

Unnever, J., Cullen, F., \& Bartkowski, J. (2006). Images of God and public support for capital punishment: Does a close relationship with a loving God matter? Criminology, 44(4), 835-866. 
Wallace, K., \& Bergeman, C. (2002). Spirituality and religiosity in a sample of African American elders: A life story approach. Journal of Adult Development, 9(2), 141-154.

Weaver, A., Pargament, K., Flannely, K., \& Oppenheimer, J. (2006). Trends in the scientific study of religion, spirituality, and health: 1965-2000. Journal of Religion and Health, 45(2), 208-214. 
APPENDIX A 


\section{APPENDIX A}

$\underline{\text { Variable }}$

Religiosity Index (Alpha .68)

Fundamentalism

Attendance

Religious strength $\underline{\text { Measurement }}$

The fundamentalism of the

respondent's religion

How often the respondent

attends religious services

The strength of the respondent's

religion $\underline{\text { Responses }}$

$1=$ liberal

$2=$ moderate

$3=$ fundamentalist

(reverse coded)

On an 8-point scale:

$0=$ never, $1=$ less than once a year, $2=$ about once or twice a year, $3=$ several times a year, $4=$ about once a month, $5=2-3$ times a month, $6=$ nearly every week, $7=$ every week, and $8=$ several times a week

On a 4-point scale:

$0=$ no religion, $1=$ somewhat strong, $2=$ not very strong, $3=$ strong

(reverse coded) 
Feeling God's love through others

How often the respondent feels God's

love through others

How often the respondent prays
Spirituality Index (Alpha .951)

Prayer

Feeling God’s love directly

Help from God
On a 6-point scale:

$1=$ never or almost never, $2=$ once in a while, $3=$ some days, $4=$ =most days, $5=$ =every day, 6=many times a day (reverse coded)

\begin{abstract}
All of variables in the index are on a 6-point scale: $1=$ never or almost never, $2=$ once in a while, $3=$ some days, $4=$ most days, $5=$ =very day, 6=many times a day (reverse coded)
\end{abstract}

How often the respondent feels God's love for them directly

How often the respondent asks for help from God in the midst of daily activities 
Guidance from God

Blessings

Being closer to God

Strength in religion/

spirituality
How often the respondent feels guided

by God in the midst of daily activities

How often the respondent feels thankful for their blessings

How often the respondent desires to be closer to God or in union with Him

How often the respondent finds strength

in their religion or spirituality 
Comfort in religion/

spirituality

Connection to life

Joy

How often, during worship or other times

connecting with God, the respondent feels joy that lifts them out of daily concerns

How often the respondent finds comfort

in their religion or spirituality

How often the respondent experiences a connection to all of life 
Lifetime Injection drug use

Lifetime crack use

Drinking problem

Illegal drug use

Demographic Variables

Age
Has the respondent ever taken injection drugs with a needle?

Has the respondent ever used crack cocaine in chunk or rock form?

Did the respondent have a drinking problem (i.e. frequently drunk, alcoholism) in the past 12 months?

Did the respondent use any illegal drugs in the past 12 months? (i.e. marijuana, cocaine, pills)
All substance abuse outcomes were dummy coded so that $0=$ no, $1=$ yes 
Sex

Race

\section{Social Bonding Variables}

Marital status

Degree
Respondent’s sex

Respondent's race

Respondent's marital status
Dummy variable created-

$0=$ female, $1=$ male

Dummy variable created-

$0=$ non-black, $1=$ =black

Dummy variable created-

$0=$ not married,

$1=$ married

On a 4-point scale:

$0=$ less than high school, 1=high school, 2=associate

or junior college, 3=bachelor's, 4=graduate 